\title{
Fuel Cell Technology Status Analysis Project: Partnership Opportunities
}

The U.S. Department of Energy's (DOE's) National Renewable Energy Laboratory (NREL) is seeking fuel cell industry partners from the United States and abroad to participate in an objective and credible analysis of commercially available fuel cell products to benchmark the current state of the technology and support industry growth. Interested fuel cell developers should contact NREL's Technology Validation Team at techval@nrel.gov.

\section{Project Features and Benefits}

Industry support - NREL supports continued industry growth by providing an independent, credible, and consistent assessment of fuel cell voltage degradation and product pricing.

Uniform analysis - Analyses are applied uniformly to the supplied data sets.

Detailed data products - NREL shares individualized data analysis results as detailed data products (DDPs) with the partners who supplied the data. The DDPs also identify specific partner contributions to the aggregated data.

Composite data products - Aggregated results are published as composite data products (CDPs), which show the technology status without identifying individual companies. Before publication, the CDPs undergo a two-stage review cycle with participating partners.

Technology status - The CDPs are a primary benchmarking tool for DOE and other stakeholders interested in tracking the status of fuel cell technologies. They highlight durability advancements, identify areas for continued development, and help set realistic price expectations at small-volume production.

Experience - This project leverages NREL's technology validation experience analyzing proprietary hydrogen and fuel cell systems and components since 2004.

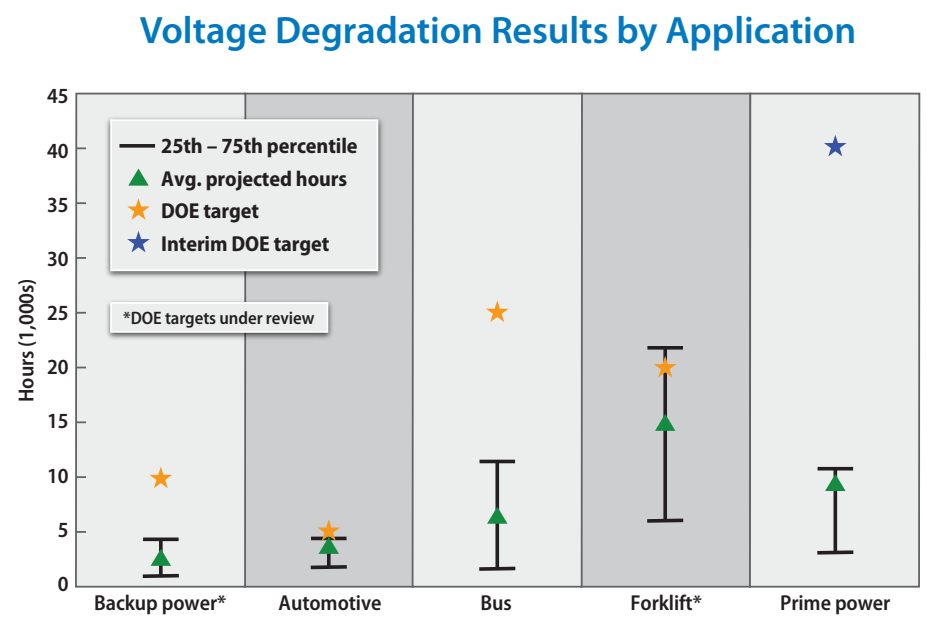

This CDP shows all the lab data sets to date for voltage degradation by application.

Voltage Degradation by Configuration and Test Condition

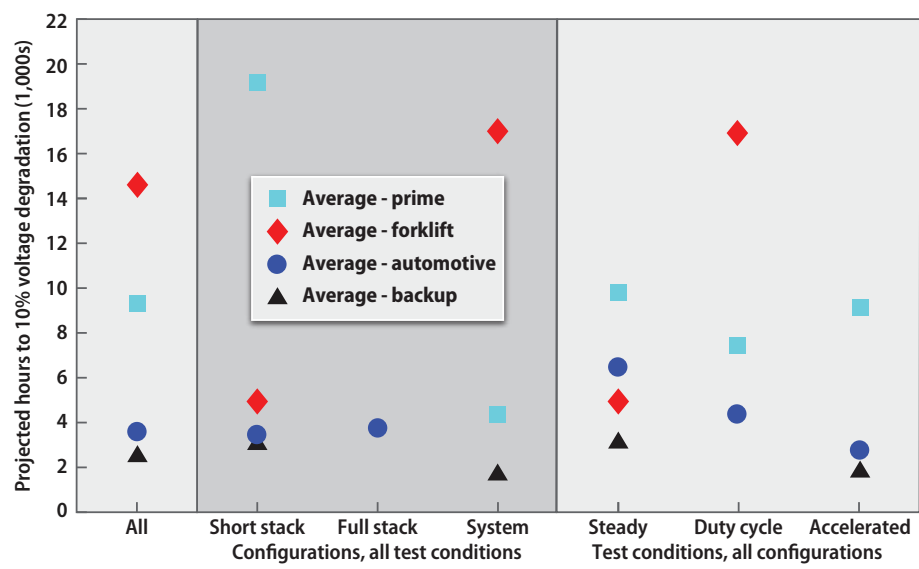

This CDP shows projected hours to $10 \%$ voltage degradation for various lab fuel cell configurations, test conditions, and applications. 


\section{How does it work?}

Participating fuel cell developers share price information about their fuel cell products and/or raw fuel cell test data related to operations, maintenance, and safety with NREL via the National Fuel Cell Technology Evaluation Center (NFCTEC). The limitedaccess, off-network NFCTEC houses the data and analysis tools to protect proprietary information.

\section{What type of data?}

- Market data on pricing, product availability, application, and quantity/type of units sold

- Lab data, including fuel cell voltage, current, and operation hours for fuel cell systems, full stacks, short stacks, and/or single cells

- Test data description, including start/end date, objective, protocol, application, fuel cell type, and reason for end of test

- Flexible data format (e.g., .xls, .csv, .txt)

- Not restricted to DOE-funded testing

\section{More Information}

Visit www.nrel.gov/hydrogen/proj_fc_analysis.html to learn more about this project and to see the CDPs published to date. Contact NREL's Technology Validation Team at techval@nrel.gov for more information about partnership opportunities.

\section{Peer Review Feedback from May 2012}

"NREL is uniquely set up to compare data sets from a variety of fuel cell developers for a range

of applications. Without this project, such comparative analysis would not be available."

"This project is essential to benchmarking the progress of fuel cell systems over time and across industries."
Average Projected Hours to $10 \%$ Voltage Drop

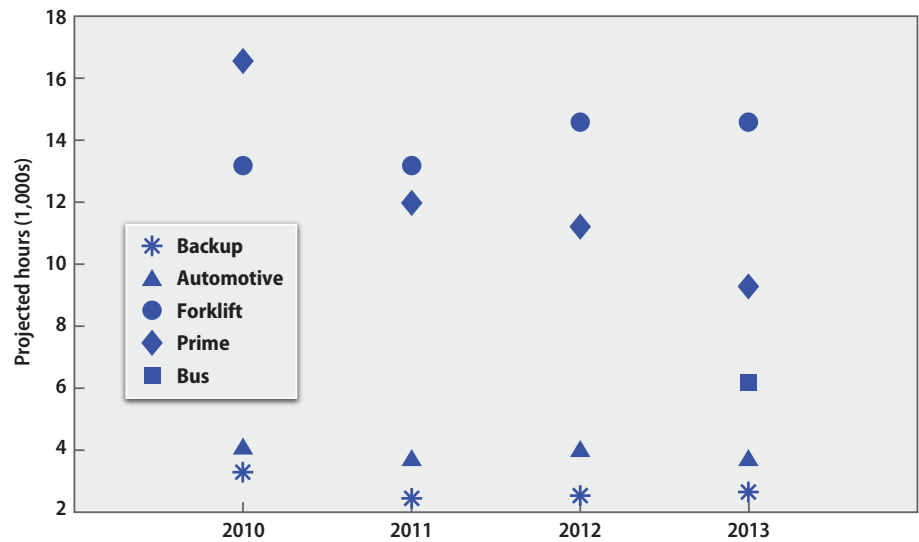

This CDP shows projected hours to $10 \%$ voltage drop for lab-tested fuel cell stacks and systems from 2010-2013.

\section{Current Fuel Cell System Price Estimates by Application}

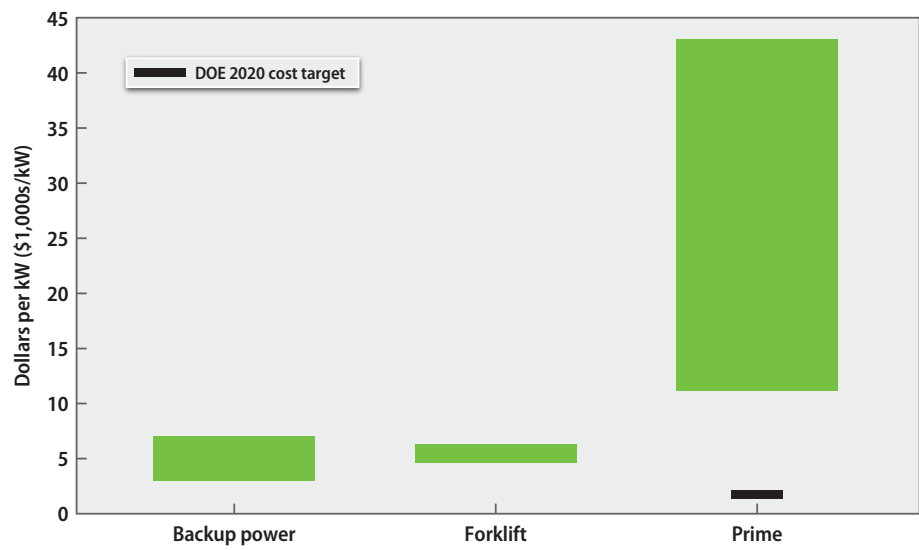

This CDP shows fuel cell system pricing (in dollars per kilowatt) for various applications.

Current Fuel Cell Price by Application and Production Rate

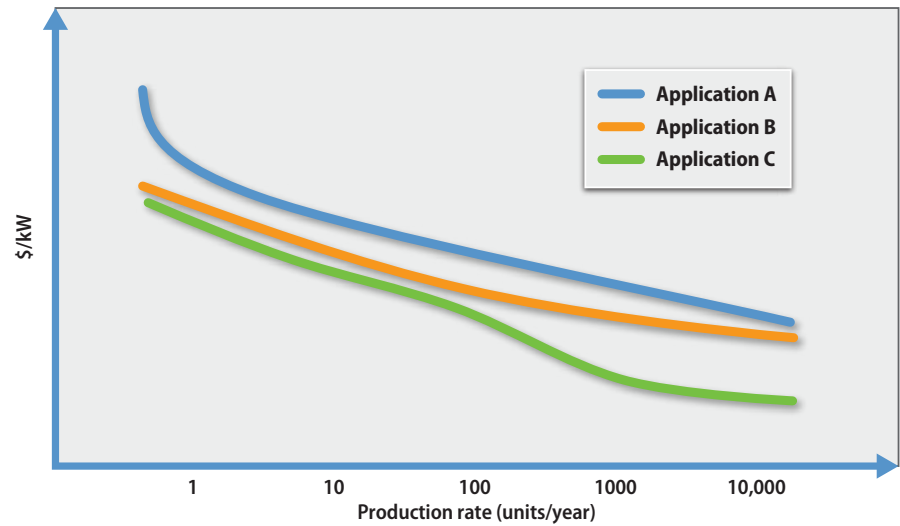

This CDP provides an example of a faux data set that shows fuel cell system pricing (in dollars per kilowatt) for various applications and production rates. 